\title{
A serodiagnostic test for tuberculosis
}

\author{
A. C. NICHOLLS \\ From Midhurst Medical Research Institute, Midhurst, Sussex
}

SYNOPSIS This study describes a simple whole cell agglutination test for tuberculosis in which phenol-killed Mycobacterium tuberculosis H37Ra is used as the antigen. The test gave positive results in 59 of 63 culture-positive cases of tuberculosis due to $M$. tuberculosis, and in 4 of 11 culturepositive cases due to other mycobacteria. Negative results were recorded in 168 of 171 control subjects. A positive result was one in which a titre of $1 / 125$ or more was recorded.

There have been many tests devised for the serodiagnosis of tuberculosis and although the doublediffusion test of Parlett and Youmans (1959) and the latex agglutination test of Duboczy and White (1969) have met with some success, there is still no satisfactory routine test available. The need is for an inexpensive and rapid test requiring the minimum of operator skill; the agglutination test is such a test, but while it has been successfully employed in the laboratory diagnosis of many diseases attempts to use the technique, dating back to Arloing and Courmont (1898), for the diagnosis of tuberculosis have proved unreliable. Historically the difficulties, summarized by Topley and Wilson (1936), were that both false positive and false negative results were common. The tendency since the haemagglutination method of Middlebrook and Dubos (1948) has been to employ sensitized-carrier techniques and precipitin tests; these, however, are also subject to difficulties in translation of results (see Parlett (1964) and Lind (1964) for full discussion of the problem). Preliminary investigations have indicated that a fluorescent antibody technique may be of use in the diagnosis of tuberculosis (Nassau and Merrick, 1970; Affronti et al, 1973), but the need for expensive equipment to obtain objective measurement will limit the use of such tests. The need for expensive equipment and reagents will probably also limit the use of the solid-phase radioimmunoassay technique of Nassau et al (1975) for the serodiagnosis of tuberculosis.

This study reports the use of a simple agglutination test, employing whole cell antigens, as a diagnostic test for tuberculosis.

Received for publication 12 May 1975.

\section{Materials and Methods}

In this study paired serum samples were taken from each of 74 patients with mycobacterial disease, 63 of whom were infected with $M$. tuberculosis, and 171 control subjects. Sera were taken by venepuncture the second sample being taken one week after the first. Sera were stored at $-20^{\circ} \mathrm{C}$ with no preservative added.

\section{PREPARATION OF ANTIGEN}

M. tuberculosis $\mathrm{H} 37 \mathrm{Ra}$ (NCTC 7417) was used as the antigen and was cultured on Lowenstein-Jensen slopes prepared in this laboratory according to the recommendations of the International Union against Tuberculosis (Jensen, 1955). Cultures were grown for six weeks at $37^{\circ} \mathrm{C}$ and the test antigen was prepared as follows:

1. The growth was emulsified from the agar slopes in sterile $0.85 \%$ saline and the washings were pooled. Subcultures were made at this stage to check the purity of the washings.

2. The pooled washing was phenolized to a final concentration of $2 \%$ phenol and incubated for three days at $37^{\circ} \mathrm{C}$ when subcultures were taken to ensure that the mycobacteria were no longer viable.

3. The phenolized bacteria were washed six times in $0.5 \%$ phenol saline and the deposit from the final centrifugation was resuspended in $0.5 \%$ phenol saline such that there were $500 \mathrm{mg}$ (wet weight) of cells per millilitre of suspension.

4. The cell suspension was heated to $80^{\circ} \mathrm{C}$ for 30 minutes with 19 times its own volume of normal sodium hydroxide, and then divided into 100 $\mathrm{ml}$ aliquots. Each aliquot was washed three times in sterile $0.3 \%$ sodium chloride solution. 
The final test suspension was prepared by suspending the final washing deposit in 300 $\mathrm{ml}$ of $0.3 \%$ sterile saline, giving a concentration of $8 \mathrm{mg}$ (wet weight) of cells per millilitre.

\section{THE AGGLUTINATION TEST}

Agglutinin levels were assessed using the modified Widal test previously described (Nicholls et al, 1975), using $0.3 \%$ saline as the diluent in order to prevent autoagglutination. A positive result was recorded when the agglutinin titre was $1 / 125$ or more.

\section{Results}

The results of agglutination tests on 64 pairs of sera taken from patients with culture-positive diagnoses of tuberculosis are given in table I. Disease due to $M$. bovis is included in this table because of the antigenic similarity between $M$. bovis and $M$. tuberculosis.

Pulmonary tuberculosis due to $M$. tuberculosis gave the most consistent results, all 54 patients having at least one serum sample with a titre of $1 / 125$ or more. The results of direct smear microscopy for evidence of acid-fast organisms were, however, generally less successful than serology. Only $29(55 \%)$ of the patients with pulmonary tuberculosis and $37(50 \%)$ of the total number of patients (74) had positive smears reported.

Staining was more successful than serology in discovering infection with non-mammalian mycobacteria; six of 10 patients with this type of infection had positive smears while only three had positive serology. In this group, seven of the patients had disease due to $M$. kansasii and three due to $M$. xenopi. Three of the $M$. kansasii infected patients had positive serology.

Details of the results obtained from the 171 pairs of control sera are given in table II. Three patients $(2 \%)$ had positive serological results. Two patients with postmortem evidence of carcinoma of the bronchus had agglutinin titres of $1 / 125$ in both serum samples, while one patient with Klebsiella pneumoniae (capsular type 3) pneumonia had

\begin{tabular}{lrcc}
\hline Final Diagnosis & No. & \multicolumn{2}{c}{ Titre of Agglutinins } \\
\cline { 2 - 4 } & & $\begin{array}{c}\text { Less than 1/125 } \\
\text { in Both Samples }\end{array}$ & $\begin{array}{l}\text { 1/125 or more } \\
\text { in Both Samples }\end{array}$ \\
\hline Carcinoma of bronchus & 26 & 24 & 2 \\
Chronic bronchitis & 80 & 80 & 0 \\
Bacterial pneumonia & 15 & 14 & 1 \\
Aspergillosis & 10 & 10 & 0 \\
Healthy controls & 40 & 40 & 0 \\
Total & 171 & 168 & 3 \\
\hline
\end{tabular}

Table II Serological results in smear and culturenegative non-tuberculosis disease

titres of $1 / 250$ in both serum samples. The titre in this patient subsided to $1 / 50$ within six months of recovery from the pneumonia. There was no in vitro agglutination of the $K$. pneumoniae by rabbit antiserum raised against $M$. tuberculosis $\mathrm{H} 37 \mathrm{Ra}$, neither was the titre removed by adsorption with $K$. pneumoniae.

\section{Discussion}

One of the major problems associated with any serodiagnostic test is the number of persons who have circulating specific antibody without further evidence of disease. It is always difficult to judge the significance of such results since they may reflect previous infection, or may be the product of cross-reaction or non-specific reaction. This problem led to simple agglutination tests for tuberculosis being largely abandoned in favour of precipitin tests and agglutination tests employing carrier particles sensitized with soluble antigen (Topley and Wilson, 1936; Parlett, 1964).

In this study many of the 'control' group patients did have detectable levels of antimycobacterial antibody but these were generally much lower than the levels recorded in the tuberculosis patients; 67 of 342 serum samples had titres of $1 / 50,106$ had titres of $1 / 25$, and 163 samples had titres of less than $1 / 25$ (recorded as 0 in this test). However, of the six remaining serum samples, two had titres of $1 / 250$ and four had titres of $1 / 125$. Since the vast majority

\begin{tabular}{|c|c|c|c|c|c|}
\hline \multirow[t]{2}{*}{ Final Diagnosis } & \multirow[t]{2}{*}{ No. } & \multicolumn{3}{|c|}{ Titre of Agglutinins } & \multirow{2}{*}{$\begin{array}{l}\text { AAFB in Direct } \\
\text { Smear }\end{array}$} \\
\hline & & $\begin{array}{l}\text { Less than } 1 / 125 \\
\text { in Both Samples }\end{array}$ & $\begin{array}{l}1 / 125 \text { or more } \\
\text { in One Sample }\end{array}$ & $\begin{array}{l}1 / 125 \text { or more } \\
\text { in Both Samples }\end{array}$ & \\
\hline $\begin{array}{l}\text { Pulmonary tuberculosis } \\
\text { Meningitis } \\
\text { Adenitis } \\
\text { Renal tuberculosis }\end{array}$ & $\begin{array}{c}54^{1} \\
5 \\
1 \\
4\end{array}$ & $\begin{array}{l}0 \\
2 \\
0 \\
2\end{array}$ & $\begin{array}{l}5 \\
1 \\
0 \\
0\end{array}$ & $\begin{array}{r}49 \\
2 \\
1 \\
2\end{array}$ & $\begin{array}{r}29 \\
2 \\
0 \\
0\end{array}$ \\
\hline Total & 64 & 4 & 6 & 54 & 31 \\
\hline
\end{tabular}

Table I Comparison of serological and microscopy results in culture-positive disease due to $\mathrm{M}$. tuberculosis ${ }^{1}$ One patient had disease due to $M$. bovis. 
of serum samples taken from tuberculosis patients had titres of $1 / 125$, it was decided that $1 / 125$ should be adopted as the significant level in differentiating positive and negative tests. The percentage of positive tests obtained from the sera of patients with pulmonary tuberculosis is high $(100 \%)$ and may give a false indication of the reliability of the test, since previous workers have shown that the percentage of positive tests is higher in groups of culture-positive patients than in groups of suspected tuberculosis patients on whom sputum culture results are awaited (Parlett, 1964). However, the percentage of extrapulmonary tuberculosis patients giving positive results is roughly equal to figures obtained by other methods (Parlett and Youmans, 1959; Duboczy and White, 1969).

The reliability of the method is increased by examining serial samples; five cases of pulmonary tuberculosis together with one case of tuberculous meningitis were serologically negative in the initial sample. The fact that the initial titres rose to higher levels after one week provided additional evidence of active infection. Demonstrable rising titres were not commonly found; apart from these six, only nine other cases showed a difference in the agglutinin titres of serial samples.

The results obtained in patients with disease due to non-mammalian mycobacteria are interesting in that only one of the 10 patients had a positive result in the first serum sample. The lower titres generally found in this group undoubtedly reflect the antigenic differences between these organisms and the test antigen. Titration of these patients' sera against the organisms isolated from this sputum revealed far higher titres. The percentage of positive tests obtained in this group is somewhat lower than that obtained by investigators using other serological tests (Parlett and Youmans, 1959; Cole et al, 1972), and it would seem that additional antigens would be required to detect these diseases. The results of the control group titrations show that approximately half (179 of 342) of the serum samples had detectable levels of antimycobacterial antibody, although only six had titres of $1 / 125$ or higher. Previous workers have found detectable levels of antibody in persons without apparent disease and have recorded similar numbers of weak positive reactions (Cole et al, 1972) although the levels in this study may be abnormally high due to the inclusion of a control group of hospital workers who tend to have higher antibody levels against $M$. tuberculosis than other community groups (Alshabkhoun et al, 1960; Lester and Colton, 1959). One control group patient had an agglutinin level of $1 / 250$ against $M$. tuberculosis although no additional evidence of tuberculosis has been discovered. The patient, a 63-year-old man, suffered an acute Klebsiella pneumonia which produced a level of $1 / 2500 \mathrm{~K}$. pneumoniae agglutinin antibody. This titre was not diminished by adsorption with $M$. tuberculosis nor was the $M$. tuberculosis titre reduced by adsorption with $K$. pneumoniae. The $K$. pneumoniae was not agglutinated by rabbit antisera raised against $M$. tuberculosis. The patient was followed in outpatient clinics for six months after which time his agglutinin titre to $M$. tuberculosis had fallen to $1 / 50$.

A comparison of this agglutination method with other techniques available for the serodiagnosis of tuberculosis indicates that the degree of reliability is similar. The advantage of this simple agglutination test is that it involves no special apparatus, little operator skill, and very little cost. Further studies are now in progress to test the reliability of the test in screening procedures.

I should like to thank the patients and colleagues who volunteered to participate in this study. In addition I am grateful to Mr F. C. Belton and his staff of the Microbiological Research Establishment for growing initial batches of $M$. tuberculosis, and to clinical colleagues in Midhurst, Birmingham, Oxford Chichester, and Carmarthen for referring an following cases.

\section{References}

Affronti, L. F., Fife, E. H., and Grow, L. (1973). Serodiagnostic test for tuberculosis. Amer. Rev. resp. Dis., 107, 822-825.

Alshabkhoun, A., Chapman, P. T., White, M. F., and DeGroat, A. (1960). A study of the double-diffusion gel precipitation test in tuberculous patients, with special reference to technical problems. Amer. Rev. resp. Dis., 81, 704-708.

Arloing, S. and Courmont, P. (1898). Sur la recherche et la $\bar{\emptyset}$ valeur clinique de l'agglutination du bacille de Koch par le $\dot{ }$ sérum sanguin de l'homme. C.R. Acad. Sci. (Paris), 127, 425-428.

Cole, R. V., Lazarus, A. W., and Hedrick, H. G. (1972). Development and evaluation of a simple latex agglutination test for diagnosis of tuberculosis. Appl. Microbiol., 24, 음

525-534.
Duboczy, B. O. and White, F. C. (1969). Further studies with $\frac{D}{O}$ the direct latex agglutination test in tuberculosis. Amer. Rev. resp. Dis., 100, 364-371.

Jensen, K. A. (1955). Towards standardisation of laboratory $\overparen{N}$ methods: Second Report of the Sub-committee of Labora- N tory Methods of the International Union against Tuberculosis. Bull. int. Un. Tuberc., 25, 89-95.

Lester, W. and Colton, R. (1959). A correlation of the results of the agar double-diffusion precipitation test with the bacteriological findings in 210 consecutive patients. In 18th Conference on the Chemotherapy of Tuberculosis, $\&$ Veterans Administration-Armed Forces, pp. 232-238.

Lind, A. (1964). The gel double diffusion precipitation test in the diagnosis of tuberculosis. Bull. int. Un. Tuberc., 34, $\overline{+}$ 37-48.

Middlebrook, G. and Dubos, R. J. (1948). Specific serum $\frac{\overparen{\Phi}}{\Phi}$ 
agglutination of erythrocytes sensitized with extracts of tubercle bacilli. J. exp. Med., 88, 521-528.

Nassau, E. and Merrick, A. J. (1970). The fluorescent antibody test in human tuberculosis: a pilot study. Tubercle (Lond.), 51, 430-436.

Nassau, E., Parsons, E. R., and Johnson, G. D. (1975). Detection of antibodies to Mycobacterium tuberculosis by solid phase radioimmunoassay. J. Immun. Methods, 6, 261-271.

Nicholls, A. C., Pease, P. E., and Green, I. D. (1975). Agglutinin response to bacterial infection in acute exacer- bations of chronic bronchitis. J. clin. Path., 28, 279-283. Parlett, R. C. (1964). The present status of the serodiagnosis of tuberculosis. Bull. int. Un. Tuberc., 34, 9-35.

Parlett, R. C. and Youmans, G. P. (1959). An evaluation of the specificity and sensitivity of a gel double-diffusion test for tuberculosis: a double blind study. Amer. Rev. resp. Dis., 80, 153-166.

Topley, W. W. C. and Wilson, G. S. (1936). In Principles of Bacteriology and Immunity, 2nd edition, p. 1036. Arnold, London.

\section{The October 1975 Issue}

\section{THE OCTOBER 1975 ISSUE CONTAINS THE FOLLOWING PAPERS}

Laboratory tests of antifungal drugs R. J. HOLT

A comparison of the in vitro activity of metronidazole, tinidazole, and nimorazole against Gramnegative anaerobic bacilli A. V. REYNOLDS, J. M. T. HAMILTON-MILLER, AND W. BRUMFITT

Comparison of antibiotic discs from different sources D. F. J. BROWN AND D. KOTHARI

\section{Bacteriocine typing of Proteus I. J. AL-JUMAILI}

An evaluation of two methods of bacteriocine typing of organisms of the genus Proteus I. J. AL-JUMAILI

Anaerobic and aerobic skin bacteria before and after skin-disinfection with chlorhexidine: An experimental study in volunteers M. L. NIELSEN, D. RAAHAVE, J. G. STAGE, AND T. JUSTESEN

Septicaemia due to Corynebacterium haemolyticum R. S. JOBANPUTRA AND C. P. SWAIN

Counter-current immunoelectrophoresis for the diagnosis of pneumococcal chest infection $\mathbf{M}$. EL-REFAIE AND C. DULAKE

False positive infectious mononucleosis serology in epilepsy P. J. HAMILTON, ELIZABETH EDMOND, AND R. J. L. DAVIDSON

Platelet counts during normal pregnancy $S$. A. SEJENY, R. D. EASTHAM, AND S. R. BAKER
Platelet aggregability in relation to impaired consciousness after head injury CH. J. VECHT, J. M. MINDERHOUD, AND C. TH. SMIT SIBINGA

Serum fibrin/fibrinogen degradation products as a prognostic index in acute myocardial infarction SAMARENDRA-LAL-CHOUDHURY, JOHN ROSSFORD EDGE, AND DEREK STANSFIELD

Multifocal malignant histiocytoma M. w. M. BRIDGER

Diagnostic significance and source of lactate dehydrogenase and its isoenzymes in cerebrospinal fluid of children with a variety of neurological disorders P. V. NELSON, W. F. CAREY, AND A. C. POLLARD

Lability of human creatine kinase isoenzymes at $37^{\circ} \mathrm{C}$ : a complication of electrophoretic separation D. A. NEALON AND A. R. HENDERSON

\section{Technical methods}

A plastic bag system which facilitates the preparation and pooling of blood components A. G. E. ALLAN, R. WILSON, P. BRAYNION, D. PEPPER, AND JOHN D. CASH

A linear graph for digoxin radioimmunoassay S. E. SMITH AND ANNA RICHTER

Book reviews

Copies are still available and may be obtained from the PUBLISHING MANAGER, BRITISH MEDICAL ASSOCIATION, TAVISTOCK SQUARE, LONDON, WC1H 9JR, price $£ 2 \cdot \mathrm{CO}$ 